\title{
Arnaud Corbic, Camus et l'homme sans Dieu
}

\section{Stefano Genetti}

\section{(2) OpenEdition \\ Journals}

Edizione digitale

URL: http://journals.openedition.org/studifrancesi/8718

DOI: $10.4000 /$ studifrancesi.8718

ISSN: 2421-5856

\section{Editore}

Rosenberg \& Sellier

\section{Edizione cartacea}

Data di pubblicazione: 1 décembre 2008

Paginazione: 699

ISSN: 0039-2944

\section{Notizia bibliografica digitale}

Stefano Genetti, «Arnaud Corbic, Camus et l'homme sans Dieu», Studi Francesi [Online], 156 (LII | III) | 2008, online dal 30 novembre 2015, consultato il 13 janvier 2021. URL: http://

journals.openedition.org/studifrancesi/8718; DOI: https://doi.org/10.4000/studifrancesi.8718

Questo documento è stato generato automaticamente il 13 janvier 2021.

\section{(c) (i) (9)}

Studi Francesi è distribuita con Licenza Creative Commons Attribuzione - Non commerciale - Non opere derivate 4.0 Internazionale. 


\title{
Arnaud Corbic, Camus et l'homme sans Dieu
}

\author{
Stefano Genetti
}

\section{NOTIZIA}

ARNAUD CORBIC, Camus et l'homme sans Dieu, Paris, Les Éditions du Cerf, 2007 («La nuit surveillée»), pp. 248.

1 Sopravvive l'uomo alla morte di Dio? in un mondo senza giustificazione superiore? Si può essere santi senza Dio? e senza i suoi sostituti laici? Su questi interrogativi riflette il docente di filosofia francescano A. Corbic in merito all'opera di Camus: Le Mythe de Sisyphe e L'Homme révolté innanzi tutto, ma anche altri scritti teorici e intimi, nonché La Peste e La Chute, radicalizzazione morale quest'ultima del dubbio metodico cartesiano ed esame di coscienza senza concessioni. Rispetto all'ateismo e all'esistenzialismo cristiano Camus viene riposizionato a partire dal dialogo che instaura con Nietzsche e con Pascal: «Je suis de ceux que Pascal bouleverse et ne convertit pas», si legge nei Carnets (p. 9). Misère e grandeur dell'uomo senza Dio, dunque, poiché una filosofia dell'uomo non può basarsi sull'ipotesi insondabile di una vita altra, bensì deve affondare le proprie radici nell'uomo stesso e nella sua definitiva provvisorietà.

2 Secondo la tripartizione canonica della creazione camusiana nei momenti dell'assurdo - «le non du monde à l'homme» - della rivolta - «le non de l'homme au monde» - e dell'amore - «le oui originaire et ultime à la vie, aux êtres, à la terre» (p. 174) - si ripercorre l'itinerario di un incroyant che dall'agnosticismo evolve verso un antiteismo connesso alla responsabilità del Creatore nell'esistenza del male. Strada facendo, si delineano i contorni di una saggezza individuale, collettiva e cosmica che identifica e supera l'inumano («le nihilisme, le ressentiment, le mal», p. 173) in nome di un amour che è consenso e riconciliazione e che l'irriducibilità stessa dell'absurde e della révolte rendono possibile: «La lucidité tragique n'interdit pas l'exigence d'humanité» (p. 174). 
3 Nel quinto capitolo, l'A. propone un parallelo tra il pensiero di Camus e quello di un suo contemporaneo: il teologo luterano tedesco Dietrich Bonhoeffer. Le idee del secondo servono a confutare puntualmente quelle del primo, in particolare sul piano cristologico. Messa alla prova della Rivelazione, l'opzione non religiosa di colui che si paragonava all'«Augustin d'avant le christianisme» (p. 168) viene ricondotta alle deviazioni del cristianesimo. Malgrado le perplessità che questo procedimento argomentativo può sollevare, il saggio di A. Corbic sottolinea con chiarezza e sensibilità la coerenza del percorso intellettuale che conduce Camus alla sofferta conquista di un umanesimo inquieto: una filosofia dell'uomo in un mondo senza Dio eppure sacro, un mondo dove Dio è presente in quanto assente.

4 In calce al volume, oltre a un aperçu chronologique, a una breve e pertinente scelta di testi, a un'abbondante bibliografia secondaria di matrice filosofica e all'indice dei nomi, si segnala agli specialisti la traduzione dal tedesco del saggio di Heinz Robert Schelette, Interprétation de la nature chez Camus (1994). 